\title{
How to Prove the Value Proposition of Spine Surgery
}

\author{
Jens Chapman ${ }^{1}$ \\ ${ }^{1}$ Department of Orthopaedics and Sports Medicine, University of \\ Washington School of Medicine, Seattle, Washington, United States
}

Evid Based Spine Care J 2014;5:73.

Spine care has come under increased scrutiny due to its substantial contribution to our unfavorable healthcare cost development. This has brought a growing awareness to the question of the relationship of the costs relative to benefits derived from spine interventions. Undoubtedly, this is probably the most pressing "hot button" topic in spine surgery around the world. While there is a general consensus that the current healthcare cost trajectories are unsustainable for just about any of the global economies, the specific methods for the calculation of value of spine care is less than straightforward as valid measurements for outcomes are just beginning to become more well defined, and calculations of cost in health remain surprisingly difficult to establish-especially when the impact of observation time frames is becoming increasingly apparent. ${ }^{1}$

In this issue of Evidence-Based Spine-Care Journal (EBSJ), our readership will find several articles that address the issue of value in spine care directly or indirectly. For instance, the impact of potentially unnecessary studies and surgical techniques (magnetic resonance imaging in adolescents and electrical stimulation to enhance spinal fusions) and a critical reflection on the safety of performing spine surgery in an outpatient setting are examples of opportunities to achieve meaningful cost savings by being more selective in our application of resources. Specifically, outpatient spine surgery performed in specialized ambulatory surgery centers has become an increasingly appealing choice in many countries for certain spine procedures in an effort to minimize the major cost factor in spine-care delivery hospitals. ${ }^{2}$

As we are looking for ways to measure outcomes, the frequently vague window of follow-up is becoming an increasingly relevant concern. In the study by Aichmair et $\mathrm{al}^{3}{ }^{3}$ attempts were made to reconnect with discectomy patients up to 10 years later. Despite some methodological limitations of achieving sizeable follow-up numbers in one of the most diverse metropolitan areas in the world-New York-with its notorious horizontal migration patterns, one of the cardinal insights of this study underscores the importance of defining follow-up parameters relative to outcomes assessments. Finally, a critical "Science in Spine" article points out the limitations and potential of "big data" mined from increasingly readily available administrative databases. These types of databases have recently gained popularity for value-related studies on spine surgery. It is important to realize what information can be gleaned from these types of investigations and where their shortcomings lie.

Staying with the theme of "value in spine care," the EBSJ readership might find interest in a prospectively randomized study that looked at 400 patients treated with epidural injections with and without steroids for lumbar spinal stenosis. In what is destined to become a hotly debated future landmark study, the widespread use of epidural steroid injections may very well be called in question as the study group who received steroids and the control group who received lidocaine alone showed no differences by 6 weeks, with higher complications reported for the technically more challenging transforaminal injections compared with interlaminar injections. ${ }^{4}$ Compared with surgery, nonoperative modalities represent a far larger component of costs in spine care. The impact of this study on reimbursement and ultimately utilization of epidural steroid injections will be interesting to see in years to come.

Finally, EBSJ would like to point its readership to the Fall 2014 Spine focus issue, created by members of AOSpine North America. The focus is on "Value-Based Health Care," and it will hopefully contribute to an enhanced understanding of this truly "hot-button" topic to spine surgeons around the world.

\section{References}

1 Porter ME. What is value in health care? N Engl J Med 2010; 363(26):2477-2481

2 Dyrda L. Deconstructing the cost of spine care: where dollars really go. Available at: http://www.beckersspine.com/spine/item/ 21024-deconstructing-the-cost-of-spine-care-where-dollars-really-go. Accessed July 21, 2014

3 Aichmair A, Du JY, Shue J, et al. Microdiscectomy for the treatment of lumbar disc herniation: an evaluation of reoperations and longterm outcomes. Evid Based Spine Care J 2014;5(2):77-86

4 Friedly JL, Comstock BA, Turner JA, et al. A randomized trial of epidural glucocorticoid injections for spinal stenosis. N Engl J Med 2014;371(1):11-21 (c) 2014 Georg Thieme Verlag KG Stuttgart · New York 10.1055/s-0034-1390026. ISSN 1663-7976.
DOI http://dx.doi.org/ 